УДК629.11.01

\title{
ШАГАЮЩЕЕ КОЛЕСО «ТУК-ТУК»
}

Д-р техн. наук А.К. Кайнарбеков, канд. техн. наук А.К. Танирбенгенров

\section{КРОКУЮЧЕ КОЛЕСО «ТУК-ТУК»}

Д-р техн. наук А.К. Кайнарбеков, канд. техн. наук А.К. Танірбенгенров

\section{STEPS WHEEL "Tuk Tuk"}

Doct. of techn. sciences A.K. Kaynarbekov, cand. of techn. sciences A.K. Tanirbengenrov

В статье рассмотрен и предложен вариант шагающего колеса «Тук - Тук» которое снабжено шестью жесткими спицами с дугообразныли ступнями без всяких сочленений. Такое колесо без лишних усложнений конструкции, обеспечивает прямолинейность движения центра ступицы $u$ мягкость приземления спицы и комфортность езды.

Ключевые слова: синтез, шагающее колесо, спица, дуги, ступица, прямолинейное движение.

У статті розглянуто та запропоновано варіант крокуючого колеса «Тук - Тук» яке забезпечене шістьма жорсткими спииями з дугоподібними ступнями без всяких зчленувань. Таке колесо без зайвих ускладнень конструкиії, забезпечує прямолінійність руху иентру маточини $i$ м'якість приземлення спиці і комфортність їди.

Ключові слова: синтез, крокуюче колесо, спиия, дуги, маточина, прямолінійний рух.

The article reviewed and offered the option of walking wheel "tuk - tuk" which is equipped with a sixspoke with stiff arched feet without any joints. Such a wheel without unnecessary complications design provides straightness of the center of the hub and spokes soft landing and driving comfort. Leg wheel "tuktuk" when driving on the road - on the plowed soil, the sand, the stubble, shows surprising results, as all its shortcomings become almost invisible. Under these conditions, the permeability is high. Wheel design is so simple that it can be stamped out of plastic materials such as nylon or even technical rubber goods. This wheel would be much safer and cheaper all kinds of wheels.

Keywords: synthesis, walking wheel, spoke, arch, nave, linear motion.

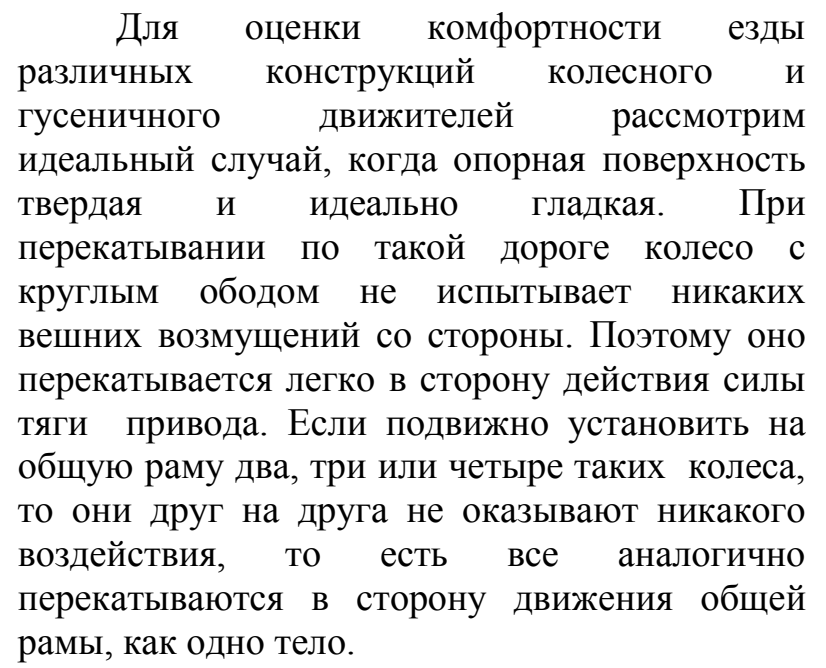

Какое решение можно предложить, чтобы первоначальное колесо, без лишних усложнений конструкции, обеспечило бы прямолинейность движения центра ступицы и мягкость приземления спицы и комфортность езды?

Есть такое решение, которое следует проанализировать. Предлагается шагающее колесо, снабженное шестью жесткими спицами с дугообразными ступнями без всяких сочленений.

Шестиспицевое шагающее колесо нужно установить в устойчивое положение, как показано на рис. 1. Параметры колеса следующие: 
длина шага $-S=Ц Ц(м)$;

длина спицы $-R(м)$;

величина максимального отклонения центра ступицы от прямолинейной траектории $-\delta(M)$

вес, падающий на ось колеса, - $G(H)$;

угол между спицами $-60^{\circ}$.

Взаимозависимость этих параметров следующая:
$G=2 N ; \quad H=R \cdot \cos 30^{\circ}=0,866 \cdot R ; \quad S=R ;$

$$
\delta=R-H=0,134 \cdot R .
$$

Для того, чтобы уменьшить величину $\delta_{1}$, проведем через центр $O$, радиус которой равен

$$
\rho=R-\delta_{1}
$$
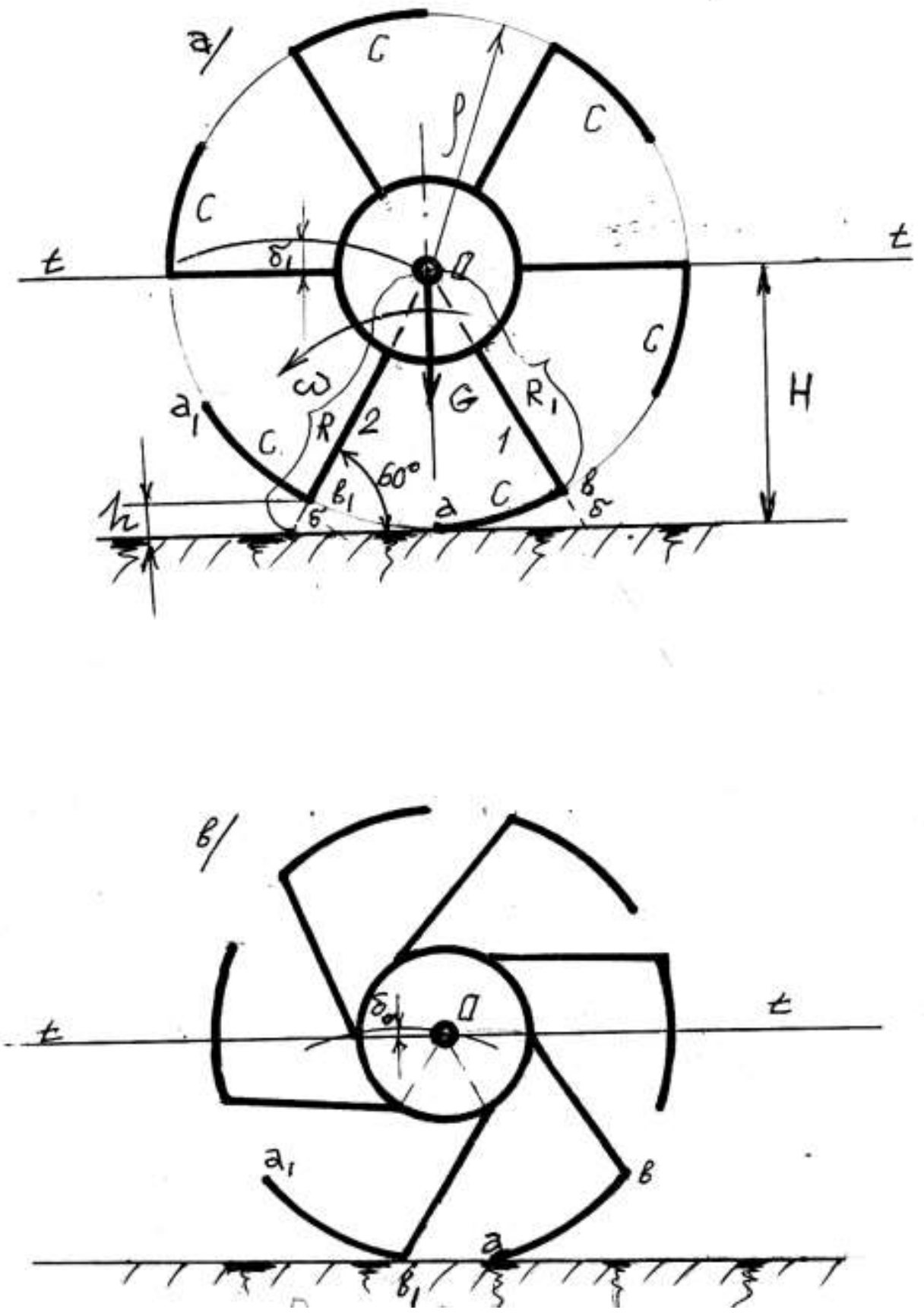

Рис. 1. Шагающее колесо «Тук-Тук» 
При этом опорные спицы укорачиваются на величину $\delta$ (рисунок 1a). Первая спица 1 пересекается с этой окружностью в точке «в» и эта точка будет теперь пяткой спицы. Окружность также касается с опорой в точке «a» и эта точка будет носком спицы 1. Так получена длина ступни первой спицы, которая равна

$$
C=R \cdot \delta / 6(M)
$$

Отложив эту длину от точки пересечения всех спиц с окружностью, получим схему шагающего колеса со ступнями. При этом колесо окажется стоящим на одной опоре в точке «a», т.е. на носке первой спицы. При этом длина спицы изменится на величину
$R_{l}=R-\delta=H / 0,866-0,134 \cdot H / 0,866=H(\mathrm{M})$.

Длина просвета $H$ оставлена без изменения.

Высота пятки второй спицы от поверхности опоры поднята на величину

$$
h=\delta \cdot \cos 30^{\circ}=0,866 \cdot \delta \quad(\mathrm{M})
$$

Из этого положения начнется шаговый режим.

Следует отметить, что из схемы шагающего колеса (рис. 2) получена схема колесно-шагающего колеса (рис. 1,a).

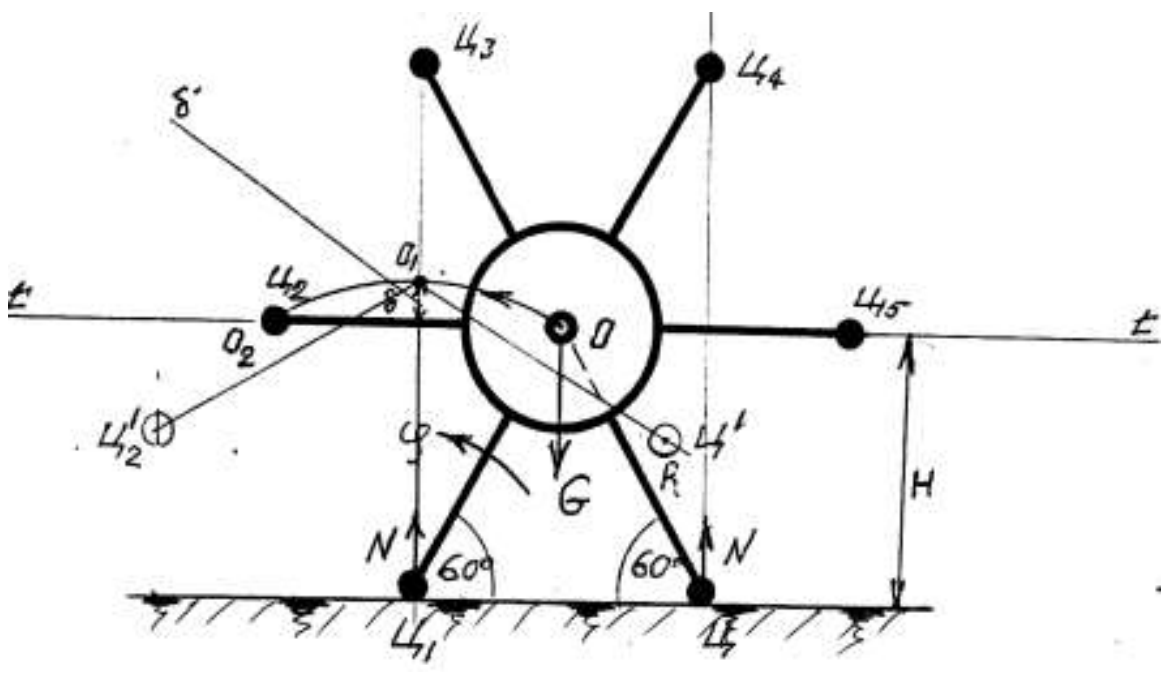

Рис. 2. Шагающее шестиспицевое колесо

В полученной схеме шагающее колесо один шаг выполняет в двух режимах шагающем и колесном.

Длина шага «вв» по дуге окружности состоит из двух частей: первая - «ав», вторая $\left\langle a \beta_{1}\right\rangle$.

Первую половину шага колесо катится на ободе (на ступне), а вторую половину шага шагает. Данное колесо можно было бы назвать колесно-шагающим, но такое название уже используется в литературе для колесношагающих движителей, где обычное колесо с ободом соединено с дополнительным шагающим механизмом, установленным на раме движителя. Поэтому данное колесо будем называть шагающим колесом «тук-тук». Такое название объясняется тем, что данное колесо со ступицей при движении в шаговом режиме падает на пятки наступающей спицы и создает звук «тук-тук».

В результате полученная схема шагающего колеса уменьшила отклонение центра ступицы на величину

$$
\delta_{1}=0,866 \delta,
$$

a ударное приземление наступающей спицы сохраняется, но уменьшилась высота падения

$$
h=0,866 \delta \text {. }
$$


Но есть дополнительное решение, которое резко уменьшит величину указанных параметров (рис. 1,6).

Изменить форму колеса можно путем изменения соединения голени с бедром. Если в первом случае (рис. 1,a) все направления спиц проходят через центр ступицы $O$, то на рис. 1,6 их направления проходят мимо центра ступицы. Тогда длина шага в шагающем режиме уменьшится по сравнению с длиной шага в колесном режиме, т.е. $a_{b_{1}}<a$. Сумма $\left(a b_{1}+a b\right)$ составляет полный шаг шагающего колеса, который равен длине перемещения центра ступицы $O$ по направлению $t$ - $t$ при повороте спицы на угол $60^{\circ}$. Самое главное при этом резко уменьшается величина отклонения $\delta$ центра ступицы от прямолинейной траектории $t$ - $t$, а следовательно, уменьшается высота падения $h$ пятки наступающей спицы и это уже положительный результат.

Если это колесо приближенно обеспечивает требование прямолинейности движения центра ступицы $O$ и минимальность высоты падения наступающей спицы, то можно бы остановиться на достигнутом. Конструкция колеса настолько проста, что его можно штамповать из полимерных материалов, таких как технический капрон или даже техническая резина. Такое колесо было бы гораздо надежнее и дешевле всех видов колес.

Шагающее колесо «тук-тук» при езде по бездорожью - по вспаханной почве, по песку, по стерне, показывает удивительные результаты, т.к. все его недостатки практически становятся незаметными. В этих условиях проходимость будет высокой.

Если это так, то опишем сущность синтеза схемы этого колеса. Для этого необходимо задать исходные данные:

$H$ - высота просвета (высота от поверхности дороги до центра ступицы);

$\delta$ - максимальная величина отклонения от прямолинейной траектории центра ступицы.

Остальные параметры колеса определяются в процессе проектирования.

Для шести спицевого колеса расчетная длина радиуса равна

$$
R_{0}=H / 0,866 \text {. }
$$

Длина расчетного шага равна $S=R_{0}$. Проведем окружность радиуса $R_{0}$ с центром в точке $O$ (рис. 3).

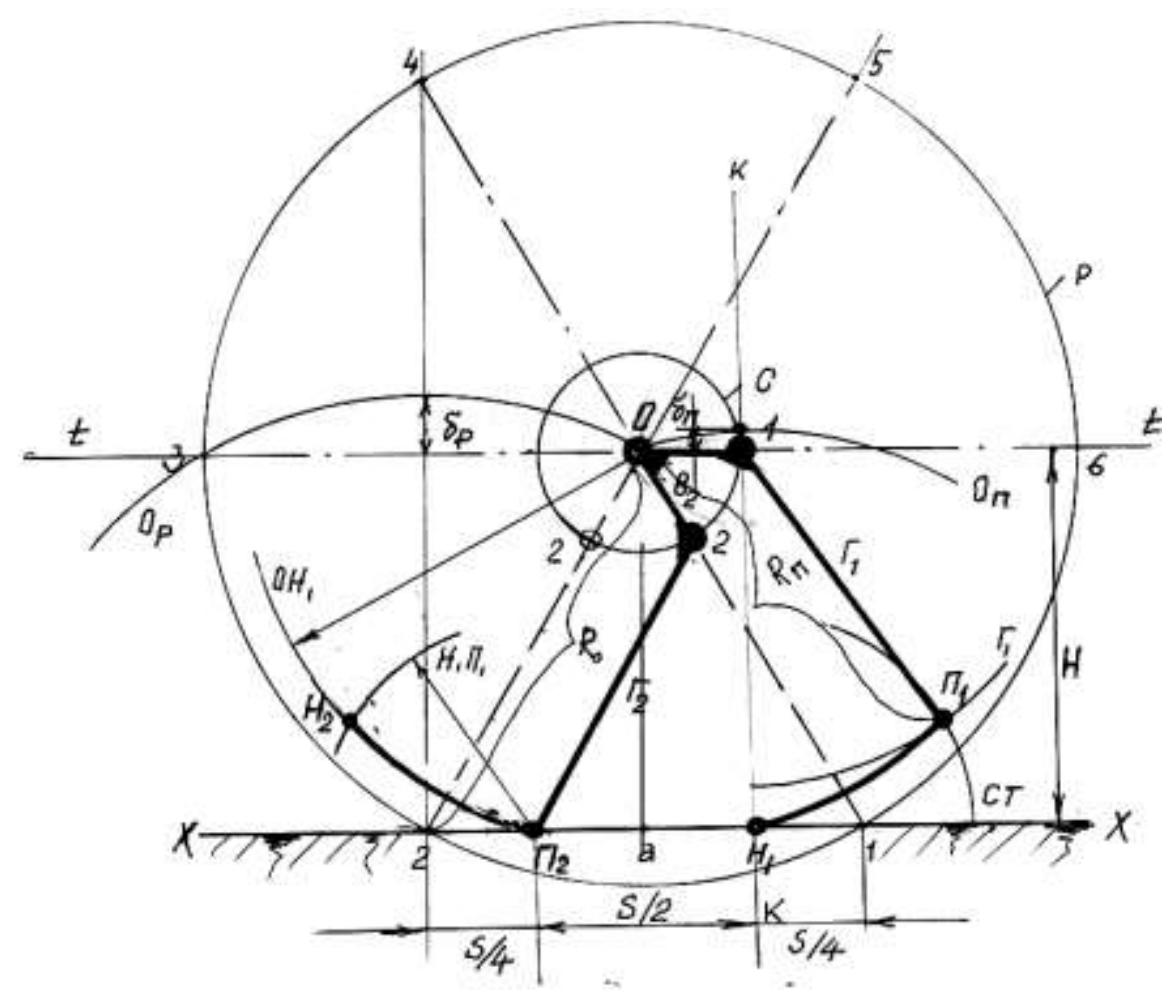

Рис. 3. К синтезу схемы шагающего колеса 
Делим окружность на шесть равных частей: $1-2,2-3,3-4,4-5,5-6$ (на чертеже радиусы $R_{0}$ окружности показаны пунктирными линиями). Через точки 1 и 2 пройдет линия опорной поверхности $\mathrm{XX}$. Длина каждого шага шестиспицевого шагающего колеса 01, 02, 03, 04, 05 и 06 равна расстоянию между двумя концевыми опорными точками смежных спиц. Например, длина расчетного шага между первой 01 и второй 02 спицами равна длине (S) отрезка 12. Делим эту длину на четыре равные части

$$
1 H_{1}=a H_{1}=a \Pi_{2}=2 \Pi_{2} .
$$

Предполагается длина шага колесного режима $\left(2 \Pi_{2}+1 H_{l}\right)$ равна длине шага $\left(\Pi_{2} H_{l}\right)$ шагового режима.

Будем считать, что жесткий расчетный радиус $R_{0}$ спицы 2 состоит из двух жестко соединенных частей: из бедра 02 и голени 22.

Проведем дугу $C$ окружности, радиус который равен длине бедренной части 02. На этой дуге делаем засечку из точки $\Pi_{2}$ радиусом, равным длине голенной части 22 , ставим точку 2. Найденная плоскость $02 \Pi_{2}$ есть новое проектное положение второй спицы 2.

Относительно проектного радиуса $R_{\Pi}$ находим другие параметры колеса.

Для определения положений первой спицы от точки 2 бедра, лежащей на окружности $C$ отложим угол $60^{\circ}$, и проведем прямую относительно центра ступицы $O$. В пересечении этой прямой с дугой окружности $C$ находим точку 1 бедренной части первой спицы.
Из найденной точки бедра 1 проводим дугу $\Gamma_{1}$ радиуса $1 \Pi_{l}$, а из опорной точки $H_{l}$ проводим другую дугу $C T$ радиуса $H_{I} \Pi_{l}=S / 2$. В пересечении этих дуг находим точку $П$.

Таким образом, найденная плоскость $O 1 \Pi_{1} H_{1}$ является жесткой плоскостью первой спицы шагающего колеса. Первая спица в данный момент приземлена и касается опорной поверхности в точке носка $H_{l}$, а точка пятки $\Pi_{l}$ приподнята. Отрезок $H_{1} \Pi_{1}$ является длиной ступни первой спицы, измеренной по хорде дуги $C T$. Кривизна дуги имеет радиус, равный длине просвета $H$.

Определим относительное положение ступни второй спицы, часть плоскости $O 2 \Pi_{2}$ которой уже известна. Для этого проводим дугу радиуса $H_{1} \Pi_{1}$ с центром в точке $\Pi_{2}$ пятки. Относительно центра ступицы $O$ проведем дугу $O H_{l}$ радиусом, равным длине отрезка $O H_{l}$. Эти дуги пересекаются в точке $H_{2}$, являющейся носком ступни $\mathrm{H}_{2} \Pi_{2}$.

Таким образом найдены положения плоскостей первой и второй спицы проектируемой схемы шагающего колеса в устойчивом положении на двух опорных точках пятки $\Pi_{2}$ и носка $H_{l}$.

Остальные четыре спицы строятся по размерам найденных двух спиц. Относительные положения элементов спиц одинаковые.

На рис. 4 показана схема шагающего колеса в положении, когда оно некоторое время остается на одной опоре. Лабораторный образец шагающего колеса «тук-тук» показан на рис. 5.

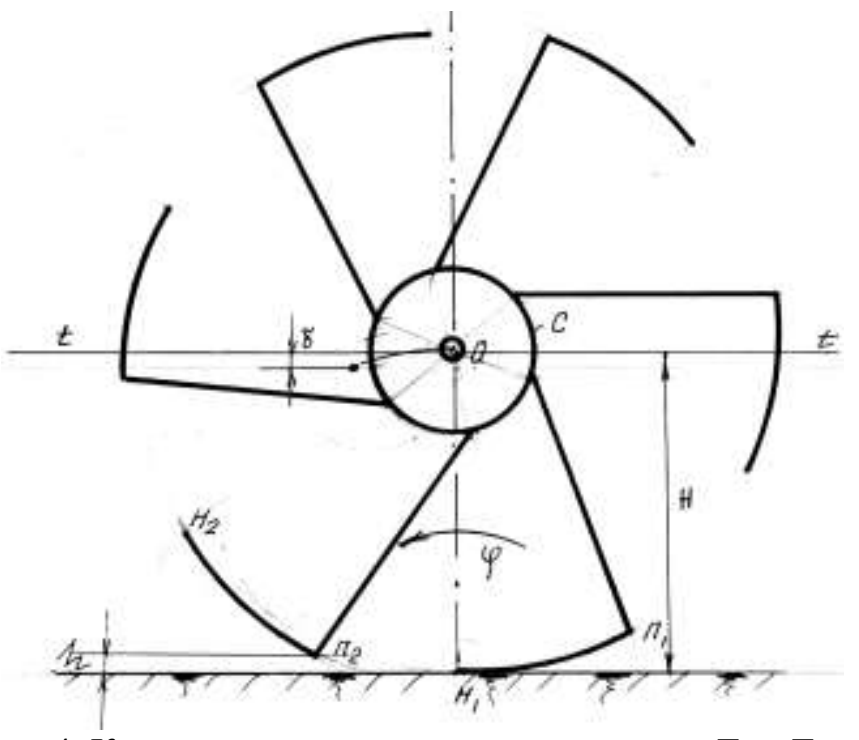

Рис. 4. К синтезу схемы шагающего колеса «Тук-Тук» 


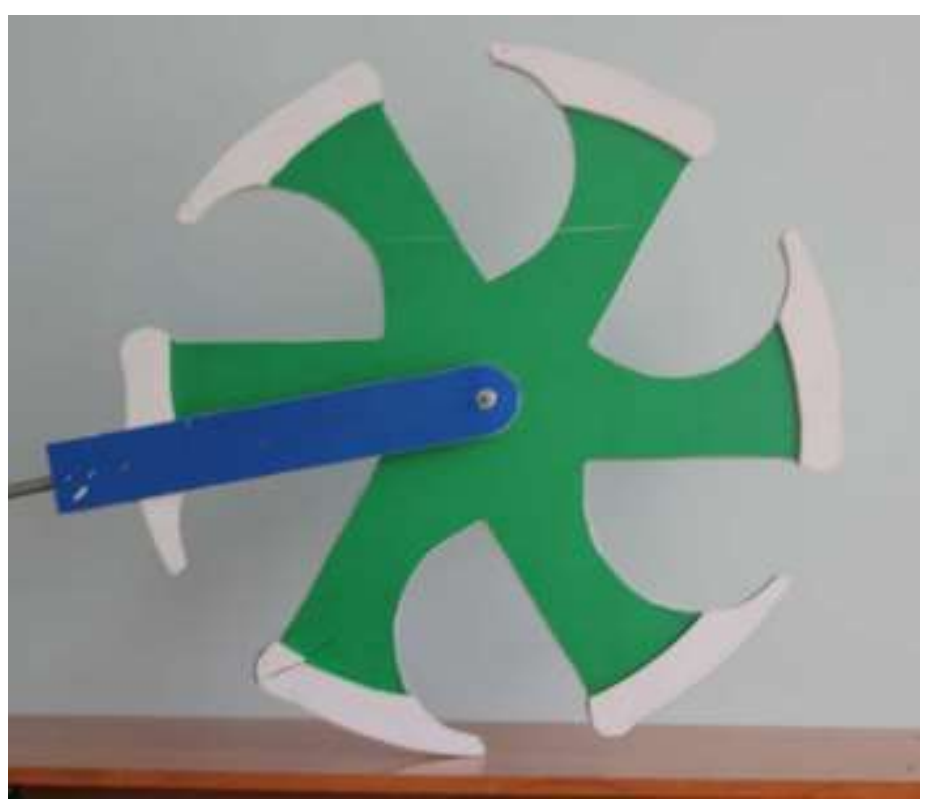

Рис. 5. Лабораторный образец шагающего колеса «тук-тук»

Увеличение длины шага шагающего режима по сравнению с длиной шага колесного режима приводит к увеличению величины отклонения центра ступицы $\delta$ от прямолинейной траектории. При этом ударное приземление спиц становится ощутимым. И наоборот, увеличение длины шага колесного режима по сравнению $\mathrm{c}$ длиной шага шагающего режима приводит к уменьшению $\delta$. Колесо при этом катится легко и звук жесткого удара спиц при приземлении уменьшается. Шагающее колесо по форме приближается к своему предшественнику колесу с круглым ободом, поэтому степень проходимости снижается.

Проектировщику шагающего колеса «тук-тук» представляется широкая возможность выбора оптимальных значений параметров.

\section{Список использованных источников}

1. Кайнарбеков, А.К. Синтез схемы шагающего колеса [Текст] / А.К. Кайнарбеков, А.М. Муратов, Р.И. Сазанбаева, Ж.Ж. Антонова. - Алматы, 2007.

2. Муратов, А.М. Синтез строения замкнутых кинематических цепей без избыточной связи [Текст] / А.М. Муратов, Р.И. Сазанбаева, Т.О. Мусин // Вестник КазАТК. - 2001. - №5.

3. Кайнарбеков, А.К. Хикаят шагающего колеса [Текст] / А.К. Кайнарбеков, А.М. Муратов, А.Д. Омаров // LAP LAMBERT Academic Publishing. - Германия, 2014.

Кайнарбеков А.К., д-р техн. наук, профеор ГУТіП ім. Д.А. Кунаева (Алматы, Республика Казахстан). Еmail:kups1@mail.ru.

Танирбенгенров А.К., канд. техн. наук, доцент ГУТіП ім. Д.А. Кунаева (Алматы, Республика Казахстан). Еmail:kups1@ mail.ru.

Kaynarbekov A.K., doct. of techn. sciences, professor at the Institute of Communications GUTiP them. D.Kunaev (Almaty, Kazakhstan).

Tanirbengenrov A.K., candidate. tehn. sciences, assoc. at the Institute of Communications GUTiP them. D.Kunaev (Almaty, Kazakhstan). 